\title{
SPECTROSCOPIC CHARACTERIZATION, X-RAY STRUCTURE AND DFT STUDIES ON 4-[3-(2,5-DIMETHYLPHENYL)-3-METHYLCYCLOBUTYL]-N- METHYLTHIAZOL-2-AMINE
}

\author{
H. Saraçoğlu ${ }^{1}$, Ö. Ekici \\ ${ }^{1}$ Department of Middle Education, Educational Faculty, Ondokuz Mayis University, Kurupelit, Samsun, Turkey \\ E-mail: hanifesa@omu.edu.tr, hanifesaracoglu@yahoo.com \\ ${ }^{2}$ Department of Chemistry, Faculty of Sciences, Firat University, Elazig, Turkey
}

Received January, 27, 2015

Revised-March, 26, 2015

\begin{abstract}
The titled molecule 4-[3-(2,5-dimethylphenyl)-3-methylcyclobutyl]-N-methylthiazol-2-amine $\left(\mathrm{C}_{17} \mathrm{H}_{22} \mathrm{~N}_{2} \mathrm{~S}\right)$ is synthesized and characterized by ${ }^{1} \mathrm{H}$ NMR, ${ }^{13} \mathrm{C}$ NMR, IR, and X-ray single crystal determination. The compound crystallizes in the monoclinic space group $P 2_{1} / c$ with $a=6.3972(4) \AA, b=9.4988(6) \AA, c=26.016(2) \AA$ and $\beta=93.496(7)^{\circ}$. In addition to the molecular geometry from the X-ray determination, vibrational frequencies and gauge, including the atomic orbital (GIAO), ${ }^{1} \mathrm{H}$ and ${ }^{13} \mathrm{C}$ NMR chemical shift values of the titled compound in the ground state are calculated using the density functional (B3LYP) method with $6-31 \mathrm{G}(d)$, $6-31++\mathrm{G}(d, p)$ and $6-311+\mathrm{G}(2 d, p)$ basis sets. The calculated results show that the optimized geometries can well reproduce the crystal structure. Moreover, the theoretical vibrational frequencies and chemical shift values show good agreement with the experimental values. The predicted nonlinear optical properties of the titled compound are greater than those of urea. DFT calculations of the molecular electrostatic potentials and frontier molecular orbitals of the titled compound are carried out at the B3LYP/6-31G $(d)$ level of theory.
\end{abstract}

DOI: $10.15372 / \mathrm{JSC} 20150715$

K e y w or d s: synthesis, thiazole, computational chemistry, X-ray structure determination, NMR spectroscopy, nonlinear optical properties.

Various thiazole derivatives show herbicidal, anti-inflammatory, antimicrobial and antiparasite activity [1,2] and also liquid crystal properties [3]. The thiazole ring is known to be a part of vitamin B1, cocarboxylase, and the cyclic system of penicillin [4]. Thiazole itself and its derivatives are of importance in biological systems as anti-inflammatory, analgesic agents and inhibitors on lipoxygenase activities $[5,6]$. The most recognized structures of the starting substances and the titled compound are given in Scheme 1.

These ligands containing cyclobutane and thiazole in their molecules seem to be suitable candidates for further chemical modifications and may be pharmacologically active and useful as ligands in<smiles>CNC(N)=S=C(C)c1csc(NC)n1</smiles>

Scheme 1. Synthetic route for the synthesis of the target compound

(C) Saraçoğlu H., Ekici Ö., 2015 
coordination chemistry. Taking into account the above observations, this compound has been synthesized in a similar manner of our ongoing research program for biologically active compounds [ 7 ].

In recent years, density functional theory (DFT) has been a shooting star in theoretical modeling. The development of ever better exchange-correlation functionals has made it possible to calculate many molecular properties with accuracies comparable with those of traditional correlated ab initio methods, with more favorable computational costs [8]. Literature surveys have revealed the high degree of accuracy of DFT methods in reproducing the experimental values in terms of geometry, dipole moment, vibrational frequency, and so on [9-15].

In this study, we present the results of a detailed investigation of the synthesis and structural characterization of 4-[3-(2,5-dimethylphenyl)-3-methylcyclobutyl]-N-methylthiazol-2-amine by single crystal X-ray diffraction, ${ }^{1} \mathrm{H}$ and ${ }^{13} \mathrm{C}$ NMR spectroscopy, and quantum chemical methods. The vibrational assignments of the titled compound in the ground state have been calculated using the DFT(B3LYP) method with $6-31 \mathrm{G}(d)$ and $6-31++\mathrm{G}(d, p)$ basis sets. The structural geometry, molecular electrostatic potential (MEP), frontier molecular orbitals (FMO), and nonlinear optical properties of the titled compound were investigated. We also make comparisons between the experiment and the calculation.

\section{EXPERIMENTAL}

Synthesis of the titled compound. To a solution of $0.0902 \mathrm{~g}$ of 1 -methylthiourea $(1 \mathrm{mmol})$ dissolved in $50 \mathrm{ml}$ of absolute ethanol, a solution of $0.251 \mathrm{~g}(1 \mathrm{mmol})$ of 2-chloro-1-[3-(2,5-dimethylphenyl)-3-methylcyclobutyl]ethanone, which was synthesized and purified according to the literature procedure [16], was added dropwise in 1-h period. After the addition of $\alpha$-haloketone, the temperature was raised to $50-55^{\circ} \mathrm{C}$ and kept at this temperature for $2 \mathrm{~h}$. The solution was cooled to room temperature and then made alkaline with an aqueous solution of $\mathrm{NH}_{3}(5 \%)$, and yellow precipitate was separated by suction, washed with aqueous $\mathrm{NH}_{3}$ solution several times and dried in air. Suitable single crystals for the crystal structure determination were obtained by slow evaporation of its ethanol solution. Light yellow crystals. Yield: $92 \%$. M.p.: $190{ }^{\circ} \mathrm{C}(\mathrm{EtOH})$.

Crystal structure determination. The data collection was performed at $296 \mathrm{~K}$ on a Stoe-IPDS-2 diffractometer equipped with graphite monochromated $\operatorname{Mo} K_{\alpha}$ radiation $(\lambda=0.71073 \AA)$. The structure was solved by direct methods using SHELXS-97 and refined by a full-matrix least-squares procedure using the SHELXL-97 program [17]. All non-hydrogen atoms were easily found from the different Fourier maps and refined anisotropically. All hydrogen atoms were included using a riding model and refined isotropically with $\mathrm{CH}=0.93$ (for the phenyl group), $\mathrm{CH}_{2}=0.97, \mathrm{CH}_{3}=0.96, \mathrm{CH}=0.98$, and $\mathrm{NH}=0.86 \AA . U_{\text {iso }}(\mathrm{H})=1.2 U_{\text {eq }}\left(1.5 U_{\text {eq }}\right.$ for the methyl group $)$. Details of the data collection conditions and parameters of the refinement process: $\mathrm{C}_{17} \mathrm{H}_{22} \mathrm{~N}_{2} \mathrm{~S}, M=287.43$, monoclinic, space group $P 2_{1} / c$, $a=6.3972(4), \quad b=9.4988(6), \quad c=26.016(2) \AA, \quad \beta=93.496(7)^{\circ}, \quad V=1577.94(19) \AA^{3}, \quad Z=4, \quad d_{\mathrm{c}}=$ $=1.210 \mathrm{~g} / \mathrm{cm}^{3}, \mu=0.198 \mathrm{~mm}^{-1}, F(000)=620$, crystal size $0.350 \times 0.227 \times 0.186 \mathrm{~mm}, \theta$ range 3.18 $28.98^{\circ}$, index ranges $-8 \leq h \leq 8,-5 \leq k \leq 12,-34 \leq l \leq 34$, 6838 reflections collected, 3577 independent $\left(R_{\text {int }}=0.062\right), 1341$ observed $(I>2 \sigma(I)), 182$ parameters, final $(I>2 \sigma(I)) R=0.076, w R=$ $=0.116$, GOOF $=1.00, \Delta \rho=0.19, \Delta \rho=-0.20 \mathrm{e} / \AA^{3}$.

Theoretical methods. DFT calculations with a hybrid B3LYP functional (Becke's threeparameter hybrid functional using the LYP correlation functional) with 6-31 $\mathrm{G}(d), 6-31++\mathrm{G}(d, p)$, and $6-311+\mathrm{G}(2 d, p)$ basis sets were performed by the Berny method $[18,19]$ using the Gaussian 03 software package [20] and the Gauss-view visualization program [21]. The calculated and scaled by 0.9772 [22 ], 0.9537 [23 ] vibrational frequencies ascertained that the structures were stable (no imaginary frequencies).

The geometry of the titled compound, together with that of tetramethylsilane (TMS), was fully optimized. ${ }^{1} \mathrm{H}$ and ${ }^{13} \mathrm{C}$ NMR chemical shifts were calculated within the GIAO approach $[24,25]$ applying B3LYP with 6-31G $(d)$ and 6-311+G( $2 d, p)$ basis sets.

To investigate the reactive sites of the titled compound the molecular electrostatic potential (MEP) was evaluated using the B3LYP/6-31G $(d)$ method. MEP, $V(r)$, at a given point $r(x, y, z)$ in the vicinity of the molecule is defined in terms of the interaction energy between the electrical charge 
Fig. 1. ORTEP III diagram of the titled compound. Displacement ellipsoids are drawn at the $30 \%$ probability level and $\mathrm{H}$ atoms are shown as small spheres of arbitrary radii

generated by the molecule electrons and nuclei and a positive test charge (a proton) located at $r$. For the system studied the $V(r)$ values were calculated as described previously using the equation [26]

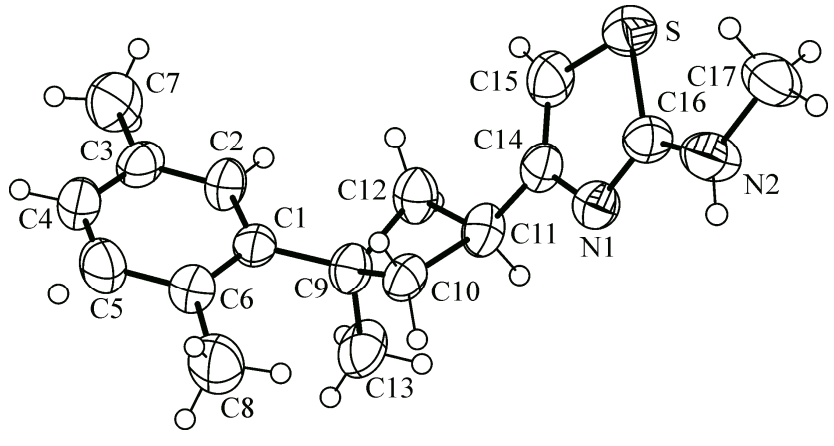

$$
V(r)=\sum\left(Z_{\mathrm{A}} /\left|R_{\mathrm{A}}-r\right|\right)-\int\left(\rho\left(r^{\prime}\right) /\left|r^{\prime}-r\right|\right) d^{3} r^{\prime},
$$

where $Z_{\mathrm{A}}$ is the charge of nucleus A located at $R_{\mathrm{A}}, \rho\left(r^{\prime}\right)$ is the electron density function of the molecule, and $r^{\prime}$ is the dummy integration variable. The linear polarizability and first hyperpolarizability properties of the titled compound were obtained by molecular polarizabilities based on theoretical calculations. In addition, the frontier molecular orbital (FMO) analysis was carried out at the same level.

\section{RESULTS AND DISCUSSION}

Description of the crystal structure. The titled compound, an ORTEP [27] view of which is shown in Fig. 1, crystallizes in the monoclinic space group $P 2_{1} / c$ with four molecules in the unit cell. The asymmetric unit in the crystal structure contains only one molecule.

The titled compound contains thiazole, dimethylphenyl, and cylobutane moieties. The thiazole and phenyl rings are planar with maximum deviations of $0.0057(28)$ and $-0.0036(22) \AA$, respectively. The dihedral angles between the dimethylphenyl plane $A(\mathrm{C} 1-\mathrm{C} 6)$, the cyclobutane plane $B(\mathrm{C} 9-$ $\mathrm{C} 12)$, and the thiazole plane $C(\mathrm{~S} / \mathrm{N} 1 / \mathrm{C} 14-\mathrm{C} 16)$ are $32.31(24)^{\circ}(A / B), 65.82(12)^{\circ}(A / C)$, and 44.12 $(17)^{\circ}(B / C)$.

In the thiazole ring, the $\mathrm{S} 1-\mathrm{C} 15$ and $\mathrm{S} 1-\mathrm{C} 16$ bond lengths (Table 1) are shorter than the accepted value for an $\mathrm{S}-\mathrm{C}\left(s p^{2}\right)$ single bond of $1.76 \AA$, resulting from the electron conjugation of $\mathrm{S} 1$

$\mathrm{T}$ a b 1 e 1

Selected theoretical and experimental geometric parameters in the titled compound

\begin{tabular}{|c|c|c|c|c|c|}
\hline Parameter & Experimental & B3LYP 6-31G $(d)$ & Parameter & Experimental & B3LYP 6-31G $(d)$ \\
\hline \multicolumn{6}{|c|}{ Bond lengths, $\AA$} \\
\hline $\mathrm{S}-\mathrm{C} 15$ & $1.718(4)$ & 1.752 & $\mathrm{~N} 2-\mathrm{C} 17$ & $1.438(4)$ & 1.451 \\
\hline $\mathrm{S}-\mathrm{C} 16$ & $1.733(4)$ & 1.774 & $\mathrm{C} 14-\mathrm{C} 15$ & $1.344(5)$ & 1.363 \\
\hline $\mathrm{N} 1-\mathrm{C} 14$ & $1.387(4)$ & 1.387 & $\mathrm{C} 9-\mathrm{C} 13$ & $1.542(5)$ & 1.541 \\
\hline $\mathrm{N} 1-\mathrm{C} 16$ & $1.316(4)$ & 1.304 & RMSE* & & 0.023 \\
\hline $\mathrm{N} 2-\mathrm{C} 16$ & $1.343(4)$ & 1.369 & Max. difference* & & 0.041 \\
\hline \multicolumn{3}{|c|}{ Bond angles, deg. } & \multicolumn{3}{|c|}{ Dihedral angles, deg. } \\
\hline $\mathrm{C} 15-\mathrm{S}-\mathrm{C} 16$ & $88.7(2)$ & 87.89 & $\mathrm{~S}-\mathrm{C} 16-\mathrm{N} 2-\mathrm{C} 17$ & $-1.5(5)$ & 19.11 \\
\hline $\mathrm{S}-\mathrm{C} 16-\mathrm{N} 1$ & $114.7(3)$ & 114.89 & $\mathrm{~N} 1-\mathrm{C} 16-\mathrm{N} 2-\mathrm{C} 17$ & $179.5(4)$ & -162.91 \\
\hline $\mathrm{N} 1-\mathrm{C} 16-\mathrm{N} 2$ & $123.2(4)$ & 123.66 & $\mathrm{C} 11-\mathrm{C} 14-\mathrm{N} 1-\mathrm{C} 16$ & $-179.4(3)$ & 179.97 \\
\hline $\mathrm{C} 14-\mathrm{N} 1-\mathrm{C} 16$ & $110.3(3)$ & 111.05 & $\mathrm{C} 10-\mathrm{C} 11-\mathrm{C} 14-\mathrm{N} 1$ & $66.0(5)$ & 69.61 \\
\hline $\mathrm{C} 11-\mathrm{C} 14-\mathrm{N} 1$ & $116.5(4)$ & 117.70 & $\mathrm{C} 12-\mathrm{C} 11-\mathrm{C} 14-\mathrm{C} 15$ & $-9.2(6)$ & -3.78 \\
\hline $\mathrm{C} 11-\mathrm{C} 14-\mathrm{C} 15$ & $128.5(4)$ & 126.57 & $\mathrm{C} 2-\mathrm{C} 1-\mathrm{C} 9-\mathrm{C} 12$ & $33.1(5)$ & 31.90 \\
\hline $\mathrm{C} 16-\mathrm{N} 2-\mathrm{C} 17$ & $122.5(4)$ & 122.42 & $\mathrm{C} 6-\mathrm{C} 1-\mathrm{C} 9-\mathrm{C} 10$ & $-49.4(5)$ & -48.90 \\
\hline RMSE* & & 0.97 & & & \\
\hline Max. difference* & & 1.93 & & & \\
\hline
\end{tabular}

* RMSE and maximum differences between the bond lengths and the bond angles computed by the theoretical method and those obtained from X-ray diffraction. 
$\mathrm{T} \mathrm{a} \mathrm{b} 1 \mathrm{e} 2$ with $\mathrm{C} 15$ and $\mathrm{C} 16$ atoms [28 ]. The $\mathrm{N} 2-\mathrm{C} 16$

Hydrogen bond geometries in the crystal structure $(\AA$, deg.) (Symmetry code: $-x, 1-y,-z$.)

\begin{tabular}{c|c|c|c|c}
\hline D-H...A & D-H & H...A & D..A & D-H...A \\
\hline N2-H2a ...N1 & 0.86 & 2.09 & $2.931(4)$ & 166
\end{tabular}
bond distance $(1.343(4) \AA)$ is shorter than a single bond [29] but longer than that of the double N1-C16 bond (1.316(4) ̊) [30,31], which suggests the existence of delocalized double bonds in the thiazole and amine moieties.

The steric interaction between the substituent groups on the cyclobutane ring means that this ring deviates significantly from planarity. In the cyclobutane ring, the $\mathrm{C} 10 / \mathrm{C} 11 / \mathrm{C} 12$ plane makes a dihedral angle of $28.44(45)^{\circ}$ with the $\mathrm{C} 12 / \mathrm{C} 9 / \mathrm{C} 10$ plane. A survey of the geometry of cyclobutanes shows the average pucker to be $29.03(13)^{\circ}$ [32 ], 28.16(3) ${ }^{\circ}$ [33 ], and 29.55(2) [ 34 ] in acyclic substituted cyclobutane rings, and the present value is in agreement with the previous reports.

The molecules are linked by the $\mathrm{N}-\mathrm{H}$...N intermolecular hydrogen bond (Table 2). The amine $\mathrm{N} 2$ atom in the molecule at $(x, y, z)$ acts as a hydrogen bond donor, via the H2a hydrogen atom, to the thiazole $\mathrm{N} 1$ atom in the molecule at $(-x, 1-y,-z)$, thus generating by translation an $R_{2}^{2}(8)$ dimer running nearly parallel to the $[0 \overline{1} 1]$ direction (Fig. 2). Apart from these hydrogen bonds, there are $\pi \ldots \pi$ interactions which stabilize the titled compound.

Optimized structure. The molecular structure of the titled compound $\left(\mathrm{C}_{17} \mathrm{H}_{22} \mathrm{~N}_{2} \mathrm{~S}\right)$ in the ground state (in vacuo) is optimized using the $\mathrm{B} 3 \mathrm{LYP} / 6-31 \mathrm{G}(d)$ method. As seen from Table 1 , most of the calculated bond lengths and bond angles are slightly different from the experimental ones. We noted that the experimental results belonged to the solid phase and theoretical calculations belonged to the gas phase. In the solid state, the experimental results are related to molecular packing, but in the gas phase, the isolated molecules are considered in the theoretical calculations. The biggest difference between the experimental and predicted bond lengths is found for the $\mathrm{S}-\mathrm{C} 16$ bond with the difference being $0.041 \AA$ for the B3LYP method, whereas the biggest difference for the bond angles is found to be $1.93^{\circ}$ for $\mathrm{C} 11-\mathrm{C} 14-\mathrm{C} 15$. Using the root mean square error (RMSE) for evaluation, RMSE values of bond lengths and angles are $0.023 \AA$ and $0.97^{\circ}$, respectively. In addition, the dihedral angles between the optimized counterparts of the titled compound are calculated as $38.72^{\circ}(A / B), 68.61^{\circ}(A / C)$, $46.61^{\circ}(B / C)$ for DFT/6-31G $(d)$. Despite the differences observed, the calculated geometric parameters are, in general, in good agreement with the X-ray structure.

IR spectroscopy. The FT-IR spectrum was obtained in $\mathrm{KBr}$ discs using a Mattson 1000 FT-IR spectrometer and is shown in Fig. 3. Harmonic vibrational frequencies of the titled compound were calculated by the DFT method with $6-31 \mathrm{G}(d)$ and $6-31++\mathrm{G}(d, p)$ basis sets, and the obtained frequencies were scaled by 0.9772 [22] and 0.9537 [23]. Using the Gauss-View molecular visualization program [21], the vibrational band assignments have been made. The calculated and experimental frequencies show differences. Two factors may be responsible for the discrepancies between the experimental and computed spectra of the investigated molecule. The first reason is that the experimental spectrum has been recorded for the compound in the solid state, while the computed spectra correspond to an isolated molecule in the gas phase. The second reason is the fact that the experimental values correspond to anharmonic vibrations, while the calculated values are harmonic vibrations [29 ]. In order to facilitate the assignment of the observed peaks we have analyzed the vibrational frequen

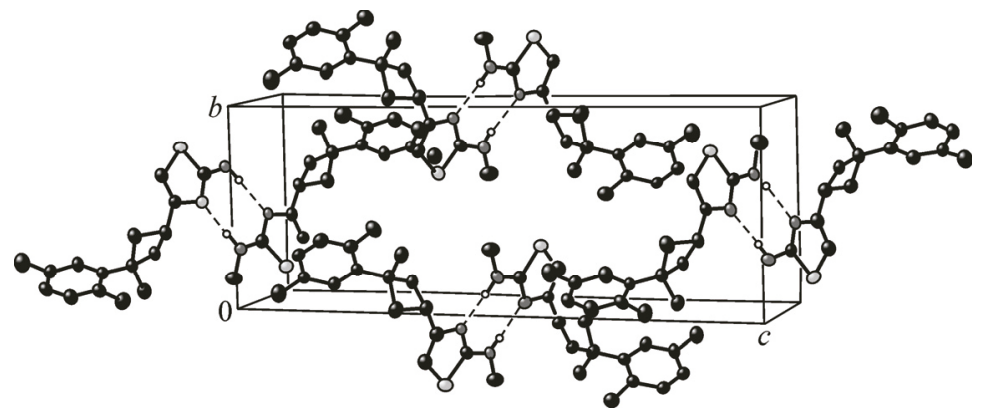

Fig. 2. Diagram showing the $\mathrm{N}-\mathrm{H} \ldots \mathrm{N}$ intermolecular hydrogen bonds in the titled compound.

Only $\mathrm{H}$ atoms involved in the hydrogen bonding interactions are shown. [Symmetry code: $-x, 1-y,-z$ ] 


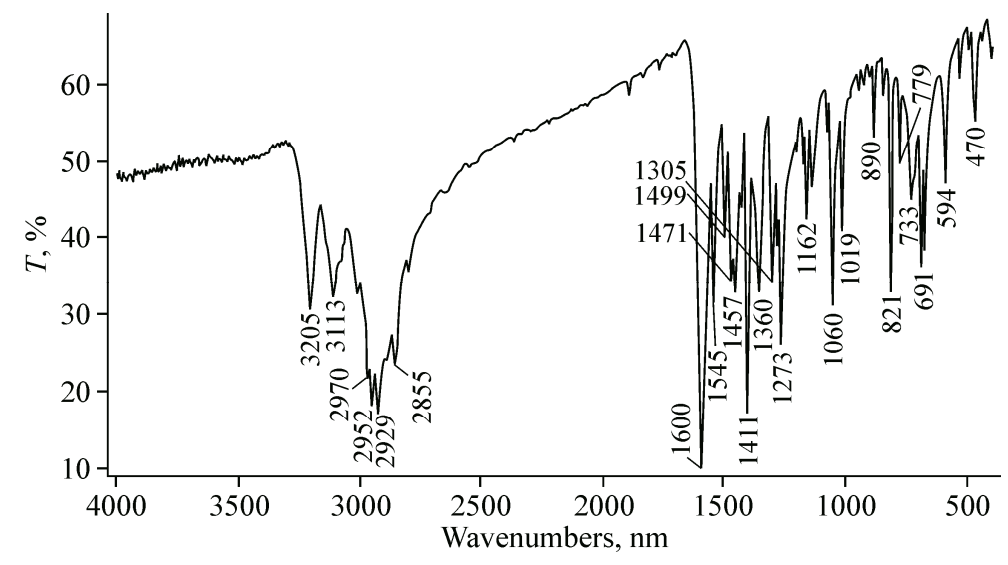

Fig. 3. FT-IR spectrum of the titled compound

cies and compared our calculation of the titled compound with their experimental data. The results and shown in Table 3.

The experimental $\mathrm{N}-\mathrm{H}$ stretching mode was observed at $3205 \mathrm{~cm}^{-1}$, which has been calculated at $3517 \mathrm{~cm}^{-1}$ at $\mathrm{B} 3 \mathrm{LYP} / 6-31 \mathrm{G}(d)$ and $3454 \mathrm{~cm}^{-1}$ at $\mathrm{B} 3 \mathrm{LYP} / 6-31++\mathrm{G}(d, p)$ levels. The experimental peak is in good agreement in the $\mathrm{NH}$ region $[35,36]$ As can be easily seen, the experimental value of

$\mathrm{Ta} \mathrm{b} 1$ e 3

Comparison of the observed and calculated vibrational spectra of the titled compound

\begin{tabular}{|c|c|c|c|c|c|c|c|}
\hline Assignments & $\begin{array}{l}\text { Experi- } \\
\text { mental }\end{array}$ & $\begin{array}{l}\text { B3LYP6- } \\
31 \mathrm{G}(d)\end{array}$ & \begin{tabular}{|} 
B3LYP6- \\
$31 \mathrm{G}++(d, p)$
\end{tabular} & Assignments & $\begin{array}{l}\text { Experi- } \\
\text { mental }\end{array}$ & $\begin{array}{c}\text { B3LYP6- } \\
31 \mathrm{G}(d)\end{array}$ & $\begin{array}{c}\text { B3LYP6- } \\
31 \mathrm{G}++(d, p)\end{array}$ \\
\hline$v \mathrm{~N}-\mathrm{H}$ & 3205 & 3517 & 3454 & $v \mathrm{C}=\mathrm{C}$ (aromatic) & 1457 & - & - \\
\hline$v_{\mathrm{s}} \mathrm{C}-\mathrm{H}$ (aromatic) & 3113 & 3114 & 3035 & $\gamma \mathrm{CH}$ (aromatic) & 1411 & 1512 & 1463 \\
\hline$v_{\text {as }} \mathrm{C}-\mathrm{H}$ (aromatic) & & 3103 & 3026 & $\beta \mathrm{CH}_{3}$ & & - & 1437 \\
\hline$v_{\text {as }} \mathrm{C}-\mathrm{H}$ (aromatic) & & 3096 & 3017 & $\beta \mathrm{CH}_{3}$ & & - & 1390 \\
\hline$v_{\text {as }} \mathrm{C}-\mathrm{H}$ (aromatic) & & 3075 & 2994 & $\alpha \mathrm{CH}_{3}$ & 1360 & 1480 & - \\
\hline$v_{\text {as }} \mathrm{C}-\mathrm{H}_{2}$ & & 3060 & 2980 & $\gamma \mathrm{NH}$ & 1305 & - & 1365 \\
\hline$v_{\text {as }} \mathrm{C}-\mathrm{H}_{3}$ & & 3050 & 2970 & $\gamma \mathrm{NH}$ & 1273 & 1411 & - \\
\hline$v_{\text {as }} \mathrm{C}-\mathrm{H}_{3}+v_{\mathrm{as}} \mathrm{C}-\mathrm{H}_{2}$ & 2970 & 3049 & 2969 & $\gamma \mathrm{CH}$ & 1162 & 1379 & 1335 \\
\hline$v_{\text {as }} \mathrm{C}-\mathrm{H}_{3}+v_{\mathrm{as}} \mathrm{C}-\mathrm{H}_{2}$ & & 3047 & 2966 & $v \mathrm{C}-\mathrm{N}$ & 1060 & 1303 & 1264 \\
\hline$v_{\mathrm{as}} \mathrm{C}-\mathrm{H}_{3}$ & & 3040 & 2958 & $v \mathrm{C}-\mathrm{C}$ (aromatic) $+\omega \mathrm{CH}_{2}$ & & 1301 & 1257 \\
\hline$v_{\text {as }} \mathrm{C}-\mathrm{H}_{3}$ & & 3022 & 2944 & $\gamma \mathrm{CH}$ & 1019 & 1278 & 1237 \\
\hline$v_{\text {as }} \mathrm{C}-\mathrm{H}_{3}$ & & 3019 & 2936 & $\beta \mathrm{CH}_{3}$ & - & 1174 & 1136 \\
\hline$v_{\mathrm{s}} \mathrm{C}-\mathrm{H}_{2}$ & & 3005 & 2925 & $\delta \mathrm{CH}_{3}$ & 890 & 1132 & 1094 \\
\hline$v_{\mathrm{s}} \mathrm{C}-\mathrm{H}_{2}$ & 2952 & 2994 & 2913 & $v \mathrm{C}-\mathrm{N}$ (aliphatic) & 821 & 1037 & 1005 \\
\hline$v \mathrm{C}-\mathrm{H}$ & & 2990 & - & $v \mathrm{C}-\mathrm{N}$ (aliphatic) & 779 & - & - \\
\hline$v_{\mathrm{s}} \mathrm{C}-\mathrm{H}_{3}$ & & 2983 & 2904 & $\omega \mathrm{CH}$ (aromatic) & 733 & 808 & 785 \\
\hline$v_{\mathrm{s}} \mathrm{C}-\mathrm{H}_{3}$ & & 2976 & 2894 & $v \mathrm{C}-\mathrm{S}$ (thiazole) & 691 & 767 & 745 \\
\hline$v_{\mathrm{s}} \mathrm{C}-\mathrm{H}_{3}$ & 2929 & 2970 & 2890 & $\beta \mathrm{CH}$ (thiazole) & & 683 & 655 \\
\hline$v_{\mathrm{s}} \mathrm{C}-\mathrm{H}_{3}$ & 2855 & 2945 & 2866 & $\beta \mathrm{CH}$ (thiazole $)+\beta \mathrm{NH}$ & & 605 & 578 \\
\hline$v \mathrm{C}=\mathrm{N}$ (thiazole) & 1600 & 1590 & 1536 & $\beta \mathrm{CH}$ (thiazole) & 594 & 573 & 563 \\
\hline$v \mathrm{C}=\mathrm{C}$ (thiazole) & 1545 & 1547 & 1498 & $\beta \mathrm{NH}+\beta \mathrm{CH}_{2}$ & 470 & 440 & - \\
\hline$v \mathrm{C}=\mathrm{C}$ (aromatic) & 1499 & - & - & $\beta \mathrm{NH}$ & & 424 & 396 \\
\hline$v \mathrm{C}=\mathrm{C}$ (aromatic) & 1471 & - & - & & & & \\
\hline
\end{tabular}

Vibrational modes: $v$, stretching; $\beta$, bending; $\alpha$, scissoring; $\gamma$, rocking; $\omega$, wagging; $\delta$, twisting; $\theta$, ring breathing; s, symmetric; as, asymmetric. 


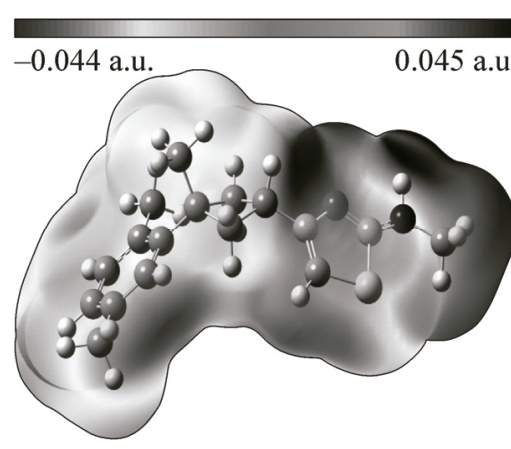

Fig. 4. Molecular electrostatic potential (MEP) map calculated at the $\mathrm{B} 3 \mathrm{LYP} / 6-31 \mathrm{G}(d)$ level

the $\mathrm{N}-\mathrm{H}$ stretching mode is smaller than the calculated frequencies because the titled compound with the amine group is involved in the hydrogen bonding. The aromatic structure shows the presence of $\mathrm{C}-\mathrm{H}$ stretching vibrations in the region $2900-3150 \mathrm{~cm}^{-1}$, which is the characteristic region for the ready identification of the $\mathrm{C}-\mathrm{H}$ stretching vibrations [37]. In the present study, the experimental $\mathrm{C}-\mathrm{H}$ stretching vibration of the titled compound is observed at $3113 \mathrm{~cm}^{-1}$, while it has been calculated at $3114 \mathrm{~cm}^{-1}$ by B3LYP6-31G $(d)$ and $3035 \mathrm{~cm}^{-1}$ by B3LYP/6-31++ $\mathrm{G}(d, p)$. The asymmetric $\mathrm{CH}_{2}$ stretching vibrations are generally observed in the region $3100-3000 \mathrm{~cm}^{-1}$, while the symmetric stretch appears between $3000 \mathrm{~cm}^{-1}$ and $2900 \mathrm{~cm}^{-1}[38,39$ 41 ]. The symmetric stretching is observed as a medium intense shoulder in the IR spectrum at $2952 \mathrm{~cm}^{-1}$. The ab initio calculation gives the frequency of these bands at $3060 \mathrm{~cm}^{-1}$ and $2980 \mathrm{~cm}^{-1}$ for the $\mathrm{CH}_{2}$ asymmetric stretch and $2994 \mathrm{~cm}^{-1}$ and $2913 \mathrm{~cm}^{-1}$ for the $\mathrm{CH}_{2}$ symmetric stretch at the $\mathrm{B} 3 \mathrm{LYP} / 6-31 \mathrm{G}(d)$ and $\mathrm{B} 3 \mathrm{LYP} / 6-31++\mathrm{G}(d, p)$ levels, respectively. The thiazole $(\mathrm{C}=\mathrm{N})$ bond stretching vibration was experimentally observed to be $1600 \mathrm{~cm}^{-1}$, while that was calculated at $1590 \mathrm{~cm}^{-1}$ at the $\mathrm{B} 3 \mathrm{LYP} / 6-31 \mathrm{G}(d)$ and $\mathrm{B} 3 \mathrm{LYP} / 6-31++\mathrm{G}(d, p)$ levels, respectively. The benzene ring modes predominantly involve $\mathrm{C}=\mathrm{C}$ bonds and the vibrational frequency is associated with the $\mathrm{C}=\mathrm{C}$ stretching modes of the carbon skeleton [42]. The $\mathrm{C}=\mathrm{C}$ stretching modes predicted at $1545-1457 \mathrm{~cm}^{-1}$ are in good agreement with the calculated values at $1547 \mathrm{~cm}^{-1}$ and $1498 \mathrm{~cm}^{-1}$.

The other calculated vibrational frequencies can be seen in Table 3. As can be seen from Table 3, there is also good agreement between the experimental and theoretical vibrational data for the others.

Molecular electrostatic potential. The molecular electrostatic potential (MEP) is related to the electron density and is a very useful descriptor in understanding the sites of the electrophilic attack and nucleophilic reactions as well as hydrogen bonding interactions [43-45]. The electrostatic potential $V(r)$ is also well suited for analyzing processes based on the "recognition" of one molecule by another, such as in drug - receptor, and enzyme - substrate interactions, because it is through their potentials that the two species first "see" each other [ 46, 47 ]. Being a real physical property, $V(r)$ can be determined experimentally by diffraction or computational methods [48 ].

MEP was calculated by the B3LYP/6-31G $(d)$ method. The red and blue regions of MEP represent the negative and positive potentials, respectively. As can be seen in Fig. 4, this molecule has one possible site of the electrophilic attack. The negative region is localized on the unprotonated N1 nitrogen atom of the thiazole ring with a minimum value of -0.044 a.u. However, maximum positive regions are localized on the N2 nitrogen atom of the amine group and the hydrogen atom of the methyl group, which can be considered as possible sites for the nucleophilic attack with maximum values of 0.045 a.u. and 0.034 a.u., respectively. According to these calculated results, the MEP map shows that the negative potential site is on the electronegative atom while the positive potential sites are around the hydrogen atoms of the methyl-amine group. These sites give information about the region where the compound can have intermolecular interactions.

${ }^{1} \mathrm{H}$ and ${ }^{13} \mathbf{C}$ NMR spectra. DFT methods treat the electronic energy as a function of the electron density of all electrons simultaneously and thus include the electron correlation effect [49]. GIAO ${ }^{1} \mathrm{H}$ and ${ }^{13} \mathrm{C}$ chemical shift values (with respect to TMS) calculated by the B3LYP/6-31G $(d)$ and B3LYP/6-311+G(2d,p) methods were compared to the experimental ${ }^{1} \mathrm{H}$ and ${ }^{13} \mathrm{C}$ chemical shift values. The ${ }^{1} \mathrm{H}$ and ${ }^{13} \mathrm{C}$ chemical shifts were measured in $\mathrm{CDCl}_{3}$. The results are given in Table 4 .

Since the experimental ${ }^{1} \mathrm{H}$ chemical shift values were not available for an individual hydrogen atom, we have presented the average values for $\mathrm{CH}_{2}$ and $\mathrm{CH}_{3}$ hydrogen atoms. The singlet observed at $6.08 \mathrm{ppm}$ is assigned to $\mathrm{H} 15$ (C15) atoms and it was calculated at $5.59 \mathrm{ppm}$ and $6.14 \mathrm{ppm}$ at the B3LYP/6-31G $(d)$ and B3LYP/6-311+G(2d,p) levels, respectively. The cyclobutane $-\mathrm{CH}_{2}-$ signals were observed at $2.45-2.58 \mathrm{ppm}$. The aromatic $\mathrm{H}$ atoms were observed at $6.84-6.95(\mathrm{H} 2, \mathrm{H} 4$, 
Theoretical and experimental ${ }^{13} \mathrm{C}$ and ${ }^{1} \mathrm{H}$ isotropic chemical shifts (with respect to TMS; all values in $\mathrm{ppm}$ ) for the titled compound

\begin{tabular}{|c|c|c|c|c|c|c|c|}
\hline \multirow[b]{2}{*}{ Atom } & \multirow{2}{*}{$\begin{array}{l}\text { Experi- } \\
\text { mental, ppm } \\
\mathrm{CDCl}_{3}\end{array}$} & \multicolumn{2}{|c|}{ Calculated chemical shifts, ppm } & \multirow[b]{2}{*}{ Atom } & \multirow{2}{*}{$\begin{array}{l}\text { Experi- } \\
\text { mental, ppm } \\
\mathrm{CDCl}_{3}\end{array}$} & \multicolumn{2}{|c|}{ Calculated chemical shifts, ppm } \\
\hline & & $\begin{array}{c}\text { B3LYP/6- } \\
31 \mathrm{G}(d)\end{array}$ & $\begin{array}{c}\mathrm{B} 3 \mathrm{LYP} / 6- \\
311 \mathrm{G}+(2 d, p)\end{array}$ & & & $\begin{array}{c}\text { B3LYP/6- } \\
31 \mathrm{G}(d)\end{array}$ & $\begin{array}{c}\mathrm{B} 3 \mathrm{LYP} / 6- \\
311 \mathrm{G}+(2 d, p)\end{array}$ \\
\hline $\mathrm{C} 1$ & 149.12 & 142.62 & 157.65 & $\mathrm{C} 16$ & 171.18 & 164.29 & 178.68 \\
\hline $\mathrm{C} 2$ & 126.20 & 120.40 & 131.78 & $\mathrm{C} 17$ & 32.01 & 31.02 & 32.52 \\
\hline $\mathrm{C} 3$ & 134.99 & 128.74 & 142.09 & $\mathrm{H} 2$ & 6.95 & 6.81 & 7.20 \\
\hline $\mathrm{C} 4$ & 126.32 & 120.16 & 130.40 & $\mathrm{H} 2 \mathrm{a}$ & 5.83 & 3.73 & 4.36 \\
\hline $\mathrm{C} 5$ & 130.86 & 124.92 & 135.65 & $\mathrm{H} 4$ & 6.84 & 6.73 & 7.12 \\
\hline C6 & 131.30 & 126.14 & 138.70 & H5 & 6.90 & 6.80 & 7.17 \\
\hline $\mathrm{C} 7$ & 20.88 & 21.72 & 23.30 & $\mathrm{H} 7 *$ & 2.23 & 2.16 & 2.31 \\
\hline $\mathrm{C} 8$ & 19.40 & 21.89 & 22.46 & $\mathrm{H} 8 *$ & 2.30 & 2.07 & 2.25 \\
\hline C9 & 39.59 & 42.57 & 46.12 & H10* & $2.45-2.58$ & 2.40 & 2.30 \\
\hline $\mathrm{C} 10$ & 41.02 & 43.03 & 45.68 & H11 & 3.55 & 3.57 & 3.51 \\
\hline C11 & 31.18 & 32.76 & 35.85 & H12* & $2.45-2.58$ & 2.49 & 2.47 \\
\hline $\mathrm{C} 12$ & 41.02 & 37.72 & 40.72 & H13* & 1.53 & 1.47 & 1.41 \\
\hline $\mathrm{C} 13$ & 27.38 & 27.52 & 28.38 & H15 & 6.08 & 5.59 & 6.14 \\
\hline $\mathrm{C} 14$ & 156.99 & 149.02 & 165.34 & $\mathrm{H} 17 *$ & 2.89 & 2.69 & 2.81 \\
\hline $\mathrm{C} 15$ & 99.05 & 101.78 & 106.87 & & & & \\
\hline
\end{tabular}

* Average.

$\mathrm{H} 5$ ) $\mathrm{ppm}$. The $\mathrm{N}-\mathrm{H}$ hydrogen atom in the amine group appears at $5.83 \mathrm{ppm}$. In the formation of the intermolecular hydrogen bond the amine group causes a deviation of the chemical shift value and therefore the $\mathrm{H}$ atom $(\mathrm{H} 2 \mathrm{a})$ contributes to the downfield resonance. ${ }^{13} \mathrm{C}$ NMR spectra of the thiazole compound show the signals at $99.05-171.18 \mathrm{ppm}$ due to $\mathrm{C}$ atoms. These signals have been calculated as $101.78-164.29 \mathrm{ppm}$ and $106.87-178.68 \mathrm{ppm}$ at the $\mathrm{B} 3 \mathrm{LYP} / 6-31 \mathrm{G}(d)$ and $\mathrm{B} 3 \mathrm{LYP} / 6-$ $311+\mathrm{G}(2 d, p)$ levels. Table 4 shows the other calculated chemical shift values. As can be seen from Table 5, calculated with a larger basis set, ${ }^{1} \mathrm{H}$ chemical shift values of the titled compound are generally in better agreement with the experimental ${ }^{1} \mathrm{H}$ shift data.

Frontier molecular orbital analysis. The frontier molecular orbitals play an important role in the electric and optical properties as well as in UV-Vis spectra and chemical reactions [ 50 ]. The distributions and energy levels of the HOMO-1, HOMO, LUMO, and LUMO+1 orbitals computed at the B3LYP/6-31G $(d)$ level for the titled compound are shown in Fig. 5.

As seen from Fig. 5, the HOMOs are mainly localized on methylthiazol-2-amine and partially on the cyclobutane fragment. However, HOMO-1 is localized on the dimethylphenyl and cyclobutane rings of the titled molecule and partially on thiazol and amine $\mathrm{N}$ atoms. The LUMOs are localized on the whole structure, except methyl groups. LUMO+1 is localized on the dimethylphenyl ring and par tially on the methylthiazol-2-amine fragment. HOMO- 1 and HOMOs are $\pi$-bonding type orbitals. In all cases, LUMO and LUMO+1s are $\pi^{*}$-antibonding type orbitals. The energy separation between the $\mathrm{HOMO}$ and LUMO is $5.549 \mathrm{eV}$, and this value indicates the energy gap of the titled compound.

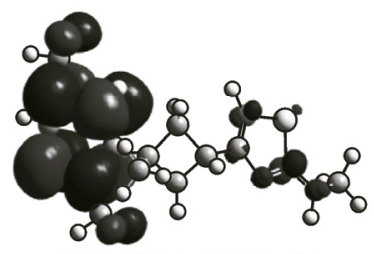

$\mathrm{LUMO}+1: 0.290 \mathrm{eV}$

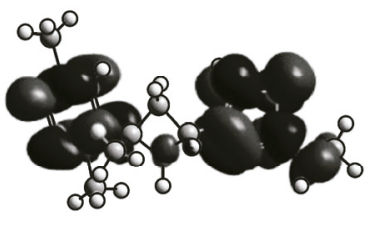

LUMO: $0.231 \mathrm{eV}$

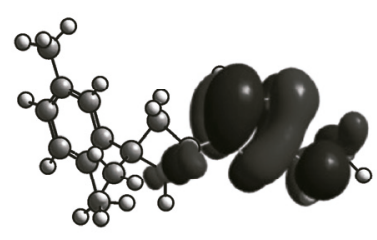

HOMO: $-5.319 \mathrm{eV}$

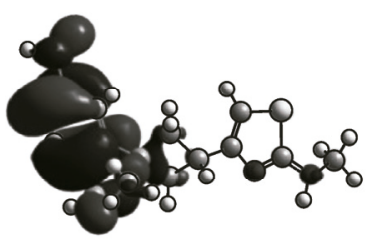

HOMO-1: $-5.992 \mathrm{eV}$

Fig. 5. Plots of the frontier orbitals of the titled compound 
Nonlinear optical effects. Nonlinear optical (NLO) effects arise from the interactions of electromagnetic fields in various media producing new fields altered in the phase, frequency, amplitude, or other propagation characteristics from the incident field [51 ]. NLO is at the forefront of the current research because of its importance in providing the key functions of the frequency shifting, optical modulation, optical switching, optical logic, and optical memory for the emerging technologies in areas such as telecommunications, signal processing, and optical interconnections [ 52-55].

The nonlinear optical response of an isolated molecule in an electric field $E_{i}(\omega)$ can be presented as a Taylor series expansion of the total dipole moment $\mu_{\text {tot }}$ induced by the field

$$
\mu_{\text {tot }}=\mu_{0}+\alpha_{i j} E_{j}+\beta_{i j k} E_{j} E_{k}+\ldots,
$$

where $\alpha_{i j}$ is the linear polarizability, $\mu_{0}$ is the permanent dipole moment, and $\beta_{i j k}$ are the first hyperpolarizability tensor components. The isotropic (or average) linear polarizability is defined as [56]

$$
\alpha_{\text {tot }}=\frac{\alpha_{x x}+\alpha_{y y}+\alpha_{z z}}{3} .
$$

The first hyperpolarizability is a third rank tensor that can be described by a $3 \times 3 \times 3$ matrix. The 27 components of the 3D matrix can be reduced to 10 components due to the Kleinman symmetry [ 57] ( $\beta_{x y y}=\beta_{y x y}=\beta_{y y x}, \beta_{y y z}=\beta_{y z y}=\beta_{z y y} ; \ldots$ likewise other permutations also take the same value). The output from Gaussian 03 provides 10 components of this matrix as $\beta_{x x x}, \beta_{x x y}, \beta_{x y y}, \beta_{y y y}, \beta_{x x z}, \beta_{x y z}, \beta_{y y z}$, $\beta_{x z z}, \beta_{y z z}, \beta_{z z z}$, respectively. The components of the first hyperpolarizability can be calculated using the following equation $[56]$ :

$$
\beta_{i}=\beta_{i i i}+\frac{1}{3} \sum_{i \neq j}\left(\beta_{i j j}+\beta_{j i j}+\beta_{j j i}\right) .
$$

Using the $x, y$, and $z$ components of $\beta$, the magnitude of the first hyperpolarizability tensor can be calculated by

$$
\beta_{\text {tot }}=\sqrt{\left(\beta_{x}^{2}+\beta_{y}^{2}+\beta_{z}^{2}\right)} .
$$
follows:

The complete equation for calculating the $\beta$ magnitude from the Gaussian $03 \mathrm{~W}$ output is given as

$$
\beta_{\text {tot }}=\sqrt{\left(\beta_{x x x}+\beta_{x y y}+\beta_{x z z}\right)^{2}+\left(\beta_{y y y}+\beta_{y z z}+\beta_{y x x}\right)^{2}+\left(\beta_{z z z}+\beta_{z x x}+\beta_{z y y}\right)^{2}} .
$$

The calculations of the total molecular dipole moment $(\mu)$, linear polarizability $(\alpha)$, and firstorder hyperpolarizability $(\beta)$ from the Gaussian output have been explained in detail previously [57 ], and DFT has been extensively used as an effective method to investigate the organic NLO materials [ 58 - 63 ]. To investigate the effects of basis sets on the NLO properties of compound $\mathbf{I}, \mu_{\text {tot }}, \alpha_{\text {tot }}$, and $\beta_{\text {tot }}$ were calculated by the B3LYP method with the $6-31 \mathrm{G}(d), 6-31+\mathrm{G}(d, p)$, and $6-31++\mathrm{G}(d, p)$ basis sets and are listed in Table 5.

From Table 5, we see that the calculated values of $\mu_{\text {tot }}, \alpha_{\text {tot }}$, and $\beta_{\text {tot }}$ slightly depend on the size of basis sets. The obtained $\mu_{\text {tot }}, \alpha_{\text {tot }}$, values with the 6-31G(d) basis set are smaller than those obtained with the other basis sets. However, the $\beta_{\text {tot }}$ value obtained by the medium size basis set is bigger than that given by a large basis set.

Urea is one of the prototypical molecules used in the study of the NLO properties of molecular

$\mathrm{T}$ a b 1 e 5 systems because there are no experimental values

HOMO-LUMO gap, total dipole moment $(\mu)$, polarizability $(\alpha)$, and first hyperpolarizability $(\beta)$ of titled compound $\mathbf{I}$

\begin{tabular}{l|c|c|c|c}
\multicolumn{1}{c|}{ Basis set } & Gap, eV & $\mu, \mathrm{D}$ & $\alpha, \AA^{3}$ & $\beta,\left(\mathrm{cm}^{5} / \mathrm{esu}\right) \times 10^{-30}$ \\
\hline $6-31 \mathrm{G}(d)$ & 5.55 & 0.70 & 30.32 & 2.02 \\
$6-31+\mathrm{G}(d)$ & 5.22 & 0.81 & 34.67 & 4.02 \\
$6-31++\mathrm{G}(d)$ & 5.14 & 0.81 & 34.85 & 3.78
\end{tabular}
for the titled compound. Therefore, it was used frequently as a threshold value for comparative purposes. It can be seen from Table 5 that the calculated $\alpha_{\text {tot }}$ and $\beta_{\text {tot }}$ values for the titled molecule are greater than those of urea $\left(\alpha_{\text {tot }}\right.$ and $\beta_{\text {tot }}$ of urea are $3.831 \AA^{3}$ and $0.3728 \times 10^{-30} \mathrm{~cm}^{5} / \mathrm{esu}$ obtained by the B3LYP/6-31G $(d)$ metho $d)$. These results indicate that the titled compound can be a potential candidate of the second order NLO material. 
To understand this phenomenon in the context of the molecular orbital theory, we examined the molecular HOMOs and LUMOs of the titled molecule. The calculated energy gaps are also listed in Table 5. The HOMO-LUMO energy gaps were calculated as $5.14-5.55 \mathrm{eV}$ for the titled molecule. As can be seen from the $\beta_{\text {tot }}$ values for the titled compound, there is an inverse relationship between the first hyperpolarizability and the HOMO - LUMO gap, allowing the molecular orbitals to overlap to have a proper electronic communication conjugation, which is a marker of the intramolecular charge transfer from the electron donating group to the electron accepting group through the $\pi$ conjugation system [64-66].

\section{CONCLUSIONS}

In this work, the compound has been characterized by ${ }^{1} \mathrm{H}$ and ${ }^{13} \mathrm{C}$ NMR, X-ray diffraction, and FT-IR techniques. The crystal structure is stabilized by $\mathrm{N}-\mathrm{H} \cdots \mathrm{N}$ hydrogen bond interactions. Density functional calculations have been performed for $\mathbf{I}$, and the calculated results show that B3LYP/6$31 \mathrm{G}(d), \mathrm{B} 3 \mathrm{LYP} / 6-31++\mathrm{G}(d, p)$, and $\mathrm{B} 3 \mathrm{LYP} / 6-311+\mathrm{G}(2 d, p)$ levels can reproduce well the crystal structure, theoretical vibrational frequencies, and chemical shift values of $\mathbf{I}$. The MEP map shows that the negative potential sites are on electronegative atoms, whereas the positive potential sites are around the hydrogen atoms. The predicted nonlinear optical (NLO) properties of the titled compound are greater than those of urea. The titled compound is a good candidate as the second-order NLO material. As a result, all of these calculations will provide helpful information for further studies on the titled compound.

Crystallographic data for the structural analysis have been deposited with the Cambridge Crystallographic Data Centre, CCDC No 874368. Copy of this information may be obtained free of charge from the Director, CCDC, 12 Union Road, Cambridge CB2 1EZ, UK (fax: +44-1223-336033; e-mail: deposit@ccdc.cam.ac.uk or www: http://www.ccdc.cam.ac.uk).

\section{REFERENCES}

1. Zollinger H. Colour Chemistry Syntheses Properties, Applications of Organic Dyes, Pigments. - Weinheim: VCH, 1991.

2. Islip P.J., Closier M.D., Neville M.C. // J. Med. Chem. - 1974. - 17, N 2. - P. 207 - 209.

3. Brown K., Cater D.P., Cavalla J.F., Green D., Newberry R.A., Wilson A.B. // J. Med. Chem. - 1974. - 17, N 11. - P. 1177 - 1181.

4. Coghi L., Lanfredi A.M.M., Tripicchio A. // J. Chem. Soc., Perkin Trans. - 1976. - 2. - P. 1808 - 1810.

5. Saprykina V.A., Vinogradova V.I., Ambartsumova R.F., Ibragimov T.F., Shakhidoyatov Kh.M. // Chem. Nat. Compd. - 2006. - 42. - P. 4470 - 4472.

6. Hadjipavlou-Litina J.D., Geronikaki A. // Arzneim Forsch. / Drug Res. - 1996. - 46. - P. 805 - 808.

7. Cukurovali A., Yilmaz I., Gur S., Kazaz C. // Eur. J. Med. Chem. - 2006. - 41. - P. 201 - 207.

8. Proft F.D., Geerlings P. // Chem. Rev. - 2001. - 101. - P. $1451-1464$.

9. Fitzgerald G., Andzelm J. // J. Phys. Chem. - 1991. - 95. - P. 10531 - 10534.

10. Ziegler T. // Pure Appl. Chem. - 1991. - 63. - P. 873 - 878.

11. Andzelm J., Wimmer E. // J. Chem. Phys. - 1992. - 96. - P. $1280-1303$.

12. Scuseria G.E. // J. Chem. Phys. - 1992. - 97. - P. $7528-7530$.

13. Dickson R.M., Becke A.D. // J. Chem. Phys. - 1993. - 99. - P. 3898 - 3905.

14. Johnson B.G., Gill P.M.W., Pople J.A. // J. Chem. Phys. - 1993. - 98. - P. 5612 - 5626.

15. Oliphant N., Bartlett R.J. // J. Chem. Phys. - 1994. - 100. - P. 6550 - 6556.

16. Akhmedov M.A., Sardarov I.K., Akhmedov I.M., Kostikov R.R., Kisin A.V., Babaev N.M. // Zh. Org. Khim. - 1991. - 27. - P. 1434.

17. Sheldrick G.M. SHELXS-97 \& SHELXL-97, University of Göttingen, Germany, 1997.

18. Schlegel H.B. // J. Comput. Chem. - 1982. - 3. - P. $214-218$.

19. Peng C., Ayala P.Y., Schlegel H.B., Frisch M.J. // J. Comput. Chem. - 1996. - 17. - P. 49 - 56.

20. Frisch M.J., Trucks G.W., Schlegel H.B. et al. GAUSSIAN-03, Rev. E.01. - Wallingford: Gaussian Inc., CT, 2004.

21. Frisch A., Dennington R.I.I., Keith T., Millam J., Nielsen A.B., Holder A.J., Hiscocks J. GaussView Reference, Version 4.0. - Pittsburgh: Gaussian Inc., 2007.

22. Scott P., Radom L. // J. Phys. Chem. - 1996. - 100. - P. $16502-16513$.

23. Zhao Y., Truhlar D.G. // J. Phys. Chem. A. - 2004. - 108. - P. $6908-6918$. 
24. Ditchfield R. // J. Chem. Phys. - 1972. - 56, N 11. - P. 5688 - 5691.

25. Wolinski K., Hinton J.F., Pulay P. // J. Am. Chem. Soc. - 1990. - 112, N 23. - P. $8251-8260$.

26. Politzer P., Murray J.S. // Theor. Chem. Acc. - 2002. - 108. - P. $134-142$.

27. Farrugia L.J. // J. Appl. Crystallogr. - 1997. - 30. - P. 565/566.

28. Allen F.H. // Acta Crystallogr. - 1984. - B40. - P. $64-72$.

29. Kowalczyk I., Bartoszak-Adamska E., Jaskólski M., Dega-Szafran Z., Szafran M. // J. Mol. Struct. - 2010. - 976. - P. $119-128$.

30. Liu G., Liu L., Jia D., Yu K. // J. Chem. Crystallogr. - 2005. - 35. - P. 497.

31. Ma Q., Lu L.-P., Zhu M.-L. // Acta Crystallogr. - 2008. - E64. - P. o2026.

32. Yüksektepe Ç., Saraçoğlu H., Koca M., Cukurovali A., Çalışkan N. // Acta Crystallogr. - 2004. - C60. - P. 0509/0510.

33. Yüksektepe Ç., Soylu S., Saraçoğlu H., Çalışkan N., Cukurovali A., Yılmaz I., Kazaz C. // Acta Crystallogr. - 2005. - E61. - P. o2384 - o2386.

34. Soylu M.S., Çalışkan N., Cukurovali A., Yılmaz I., Büyükgüngör O. // Acta Crystallogr. - 2005. - C61. - P. $0725-0727$.

35. Roeges N.P.G. A Guide to the Complete Interpretation of Infrared Spectra of Organic Structures, Wiley, Chichester, ch. 9, 1994.

36. Herzberg G. Molecular Spectra, Molecular Structure. - New York: Van Nostrand, 1945. - Vol. 2, chap. 3, sect. 3.

37. Teimouri A., Emami M., Chermahini A.N., Dabbagh H.A. // Spectrochim. Acta. - 2009. - 71A. - P. 1749 1755.

38. Hubert Joe I., Aruldhas G., Anbukumar S., Ramasamy P. // Cryst. Res. Technol. - 1994. - 29. - P. 685 692.

39. Litvinov G. Proc. Int. Conf. Raman Spectrosc., 13th, Wurzburg, Germany, 1992.

40. Furic K., Mohacek V., Bonifacic M., Stefanic I. // J. Mol. Struct. - 1992. - 267. - P. 39 - 44.

41. Lan G., Wang H., Zheng J. // Spectrochim. Acta. - 1990. - 46A. - P. $1211-1216$.

42. Teimouri A., Chermahini A.N., Taban K., Dabbagh H.A. // Spectrochim Acta. - 2009. - 72A. - P. 369 377.

43. Scrocco E., Tomasi J. // Adv. Quant. Chem. - 1978. - 11. - P. 115 - 193.

44. Luque F.J., Lopez J.M., Orozco M. // Theor. Chem. Acc. - 2000. - 103. - P. 343 - 345.

45. Okulik N., Jubert A.H. // Internet Electron J. Mol. Des. - 2005. - 4. - P. 17 - 30.

46. Politzer P., Laurence P.R., Jayasuriya K. // Environ. Health Perspect. - 1985. - 61. - P. 191 - 202.

47. Scrocco E., Tomasi J. // Top. Curr. Chem. - 1973. - 7. - P. $95-170$.

48. Politzer P., Truhlar D.G. Chemical Applications of Atomic, Molecular Electrostatic Potentials. - N. Y.: Plenum Press, 1981.

49. Demir S., Dinçer M., Korkusuz E., Yıldırım I. // J. Mol. Struct. - 2010. - 980. - P. 1 - 6.

50. Fleming I. Frontier Orbitals, Organic Chemical Reactions. - London: John Wiley, 1976.

51. Sun Y.X., Hao Q.L., Wei W.X., Yu Z.X., Lu L.D., Wang X., Wang Y.S. // J. Mol. Struct.: THEOCHEM. - 2009. - 904. - P. $74-82$.

52. Andraud C., Brotin T., Garcia C., Pelle F., Goldner P., Bigot B., Collet A. // J. Am. Chem. Soc. - 1994. - 116. - P. $2094-2102$.

53. Geskin V.M., Lambert C., Bredas J.L. // J. Am. Chem. Soc. - 2003. - 125. - P. 15651 - 15658.

54. Nakano M., Fujita H., Takahata M., Yamaguchi K. // J. Am. Chem. Soc. - 2002. - 124. - P. 9648 - 9655.

55. Sajan D., Joe H., Jayakumar V.S., Zaleski J. // J. Mol. Struct. - 2006. - 785. - P. 43 - 53.

56. Zhang R., Du B., Sun G., Sun Y.X. // Spectrochim. Acta. - 2010. - 75A. - P. $1115-1124$.

57. Kleinman A. // Phys. Rev. - 1962. - 126. - P. 1977 - 1979.

58. Thanthiriwatte S., Nalin de Silva K.M. // J. Mol. Struct.: THEOCHEM. - 2002. - 617. - P. 169 - 175.

59. Sun Y.X., Hao Q.L., Yu Z.X., Wei W.X., Lu L.D., Wang X. // Mol. Phys. - 2009. - 107. - P. 223 - 235.

60. Ahmed B., Feki H., Abid Y., Boughzala H., Minot C., Mlayah A. // J. Mol. Struct. - 2009. - 920. - P. 1 - 7.

61. Abraham P., Sajan D., Shettigar V., Dharmaprakash S.M., Nemec I., Joe I.H., Jayakumar V.S. // J. Mol. Struct. - 2009. - 917. - P. $27-36$.

62. Sagdinc S.G., Esme A. // Spectrochim. Acta. - 2010. - 75A. - P. 1370 - 1376.

63. Ahmed B., Feki H., Abid Y., Boughzala H., Minot C. // Spectrochim. Acta. - 2010. - 75A. - P. 293 - 298.

64. Ruiz Delgado C., Hernandez V., Casado J., Lopez Navarre J.T., Raimundo J.M., Blanchard P., Roncali J. // J. Mol. Struct.: THEOCHEM. - 2004. - 709. - P. 187 - 193.

65. Ruiz Delgado C., Hernandez V., Casado J., Lopez Navarre J.T., Raimundo J.M., Blanchard P., Roncali J. // J. Mol. Struct. - 2003. - 651-653. - P. $151-158$.

66. Abraham P., Sajan D., Shettigar V., Dharmaprakash S.M., Nemec I., Hubert Joe I., Jayakumar V.S. // J. Mol. Struct. - 2009. - 917. - P. 27 - 36. 